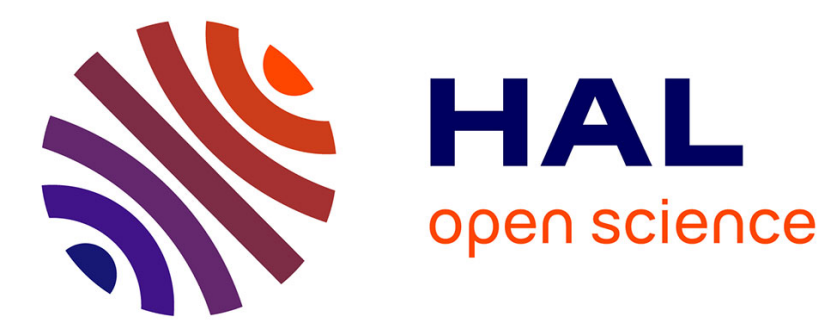

\title{
Solid-Liquid Equilibrium Prediction for Binary Mixtures of Ar, O2, N2, Kr, Xe, and CH4 using the LJ-SLV-EoS
}

Marco Campestrini, Paolo Stringari, Philippe Arpentinier

\section{To cite this version:}

Marco Campestrini, Paolo Stringari, Philippe Arpentinier. Solid-Liquid Equilibrium Prediction for Binary Mixtures of Ar, O2, N2, Kr, Xe, and CH4 using the LJ-SLV-EoS. Fluid Phase Equilibria, 2014, 379, pp.139-147. 10.1016/j.fluid.2014.07.020 . hal-01067216

HAL Id: hal-01067216

https://hal-mines-paristech.archives-ouvertes.fr/hal-01067216

Submitted on 23 Sep 2014

HAL is a multi-disciplinary open access archive for the deposit and dissemination of scientific research documents, whether they are published or not. The documents may come from teaching and research institutions in France or abroad, or from public or private research centers.
L'archive ouverte pluridisciplinaire HAL, est destinée au dépôt et à la diffusion de documents scientifiques de niveau recherche, publiés ou non, émanant des établissements d'enseignement et de recherche français ou étrangers, des laboratoires publics ou privés. 


\title{
Solid-Liquid Equilibrium Prediction for Binary Mixtures of
}

\section{$\mathrm{Ar}, \mathrm{O}_{2}, \mathrm{~N}_{2}, \mathrm{Kr}, \mathrm{Xe}$, and $\mathrm{CH}_{4}$ using the LJ-SLV-EoS}

\author{
Marco Campestrini $^{\mathrm{a}}$, Paolo Stringari ${ }^{\mathrm{a}, *}$, Philippe Arpentinier $^{\mathrm{b}}$ \\ ${ }^{a}$ MINES ParisTech, PSL Research University, CTP, - Centre Thermodynamics of Processes, 35, rue Saint Honoré, \\ 77300 Fontainebleau, France. \\ ${ }^{a}$ Air Liquide - Centre de Recherche Claude-Delorme, 1 Chemin de la Porte des Loges BP 126, 78354 Jouy-en- \\ Josas, France
}

* Corresponding author. Tel.: +33 (0)1 646948 57. E-mail address: paolo.stringari@mines-paristech.fr 


\begin{abstract}
In a previous paper, authors used molecular simulation data for Lennard-Jones fluids for the regression of the binary interaction parameters of the LJ-SLV-EoS. The binary interaction parameters of the EoS have been expressed as simple functions of the ratios $\sigma_{11} / \sigma_{22}$ and $\varepsilon_{11} / \varepsilon_{22}$. This procedure allows obtaining a qualitative prediction of the solid-liquid phase behavior of mixtures composed of simple fluids. This work presents the predicted phase diagrams including solid phases for binary mixtures composed of argon, oxygen, nitrogen, krypton, xenon, and methane. Predictions are in qualitative agreement with the phase behavior documented by the experimental data available from the literature. The adopted procedure allows producing a qualitative reasonable phase diagram for mixtures knowing the Lennard-Jones parameters of the mixture components. The comparison with literature data shows that the adopted procedure is suitable for predicting the solid-liquid behavior of the mixture, distinguishing among eutectic, solid solution, solid-liquid azeotrope.
\end{abstract}

Keywords: cryogenic processes, equation of state, Lennard-Jones, phase diagram, solid-liquid equilibrium. 


\section{Introduction}

The SLV-EoS, proposed by A. Yokozeki [1], allows representing solid, liquid, and vapor phases for a pure substance with a single analytical equation. The equation can be extended to mixtures. In this last case, four binary interaction parameters must be determined $\left(\mathrm{k}_{\mathrm{ij}}, \mathrm{m}_{\mathrm{ij}}, \mathrm{n}_{\mathrm{ij}}\right.$, and $\left.\mathrm{l}_{\mathrm{ij}}\right)$. The SLV-EoS has been applied for representing thermodynamic properties of pure compounds (argon, methane, and carbon dioxide), and mixtures (methane + carbon dioxide [1] and benzene + cyclohexane [2]). The SLV-EoS has been applied for modeling the phase equilibrium including hydrates for the mixture methane + water [3] and [4] carbon dioxide + water [4] and [5]. The application of the SLV-EoS for representing the phase behavior of hard sphere mixtures has been presented in [6] and the phase behavior of indoles has been studied in [7]. Authors of the present paper studied modifications of the SLV-EoS for modeling mixtures of carbon dioxide + methane, ethane, and propane [8]. Same authors adapted the equation to the representation of the phase behavior of Lennard-Jones molecules [9]. The SLV-EoS revealed being very interesting for representing solid, liquid, and vapor phases of substances involved in cryogenic processes [10] and [8].

Cryogenic processes, like air distillation, natural gas treatment, or production of liquefied natural gas (LNG), often enter conditions at which several components can be in solid phase. Solid-liquid and solid-vapor equilibria for the mixtures involved in these cryogenic processes are poorly investigated from the experimental point of view. Furthermore, the cited cryogenic processes involve small molecules, which behavior is characterized by partial or total solubility in the solid phase. It means that several type of solid-liquid phase diagrams can be formed by these molecules, like solid solutions, eutectic with partial miscibility, or solid-liquid azeotrope. 
The combination of these two factors, lack of experimental data from one side, variety of phase equilibrium behaviors from the other side, results in a difficulty in predicting the type of solidliquid phase diagram for these molecules.

The phase behavior of molecules like argon, krypton, xenon, and methane, usually involved in cryogenic processes like air distillation, is well approximated by molecular simulation of Lennard-Jones molecules. In a previous work [9], authors regressed binary interaction parameters of the LJ-SLV-EoS for representing the phase behavior, involving solid phases, for LennardJones binary mixtures with diameter ratio $\sigma_{11} / \sigma_{22}$ ranging from 0.85 to 1 , and well-depth ratio $\varepsilon_{11} / \varepsilon_{22}$ ranging from 0.625 to 1.6 at reduced pressure $P^{*}=P \sigma_{11}{ }^{3} / \varepsilon_{11}=0.002$. Figure 1 shows the phase behaviors obtained in [9] for different values of $\sigma_{11} / \sigma_{22}$ and $\varepsilon_{11} / \varepsilon_{22}$. In [9], it has been shown that the obtained binary interaction parameters are smoothed functions of the ratios $\sigma_{11} / \sigma_{22}$ and $\varepsilon_{11} / \varepsilon_{22}$. In the present work, mathematical expressions for $k_{i j}, m_{i j}, n_{i j}$, and $l_{i j}$ as functions of $\sigma_{11} / \sigma_{22}$ and $\varepsilon_{11} / \varepsilon_{22}$ are presented. These functions allow predicting the binary interaction parameters $\mathrm{k}_{\mathrm{ij}}, \mathrm{m}_{\mathrm{ij}}, \mathrm{n}_{\mathrm{ij}}$, and $\mathrm{l}_{\mathrm{ij}}$ once the parameters $\sigma$ and $\varepsilon$ of the molecules composing the mixture are known. These binary interaction parameters, inserted in SLV-EoS mixing rules, allow obtaining a qualitatively correct representation of the phase equilibrium behavior of real mixtures composed of molecules that behave in a LJ-like manner. The present study has been extended also to diatomic molecules oxygen and nitrogen, key-components in the cryogenic air distillation process. The objective of this work is showing the prediction capability of this method for representing the phase behavior of small molecules. The model can be used for obtaining reliable predictions of the mixture phase behavior, if data are not available. Otherwise, the values of the binary interaction parameters can be used as initial estimations in a parameter regression procedure, if experimental data are available. 


\section{Equation of state for pure substances}

The SLV-EoS proposed by A. Yokozeki [1] is reported in Eq. (1).

$$
P=\frac{R T}{v-b} \frac{v-d}{v-c}-\frac{a}{v^{2}}
$$

In Eq. (1), $P$ is the pressure, $R$ is the gas constant, $T$ is the temperature, $v$ the molar volume, $c$ the liquid covolume, $b$ the solid covolume, $a$ the parameter for the attractive term; when $v=d$ the repulsive term in Eq. (1) is null.

This model has been applied for representing the pressure-temperature equilibrium behavior of the substances argon, oxygen, nitrogen, krypton, xenon, and methane.

The parameters $a$ and $b$ in Eq. (1) are temperature dependent functions and their expressions are given in Eqs. (2) and (3).

$$
\begin{aligned}
& a(T)=\frac{\left(R T_{c}\right)^{2}}{P_{c}}\left[a_{0}+a_{1} T_{r} \exp \left(-a_{2} T_{r}^{n}\right)\right] \\
& b(T)=v_{c}\left[b_{0}+b_{1} \exp \left(-b_{2} T_{r}^{m}\right)\right]
\end{aligned}
$$

In Eqs. (2) and (3), $T_{r}=T / T_{c}$ is the reduced temperature, $a_{0}, a_{1}, a_{2}, n, b_{0}, b_{1}, b_{2}$, and $m$ are parameters. $T_{c}, P_{c}$, and $v_{c}$ are temperature, pressure, and volume at the critical point. While $T_{c}$ and $P_{c}$ correspond to the experimental values for these quantities, $v_{c}$ (or $Z_{c}$ ) is used as a parameter.

The system defined by Eqs. (1) to (3) presents a total of nine parameters. Those parameters have been regressed through the procedure of regression presented in reference [8], which makes Eq. (1) rigorous in the representation of temperature and pressure at the critical and triple points. Values of pressure and temperature at critical and triple points for argon, oxygen, nitrogen, 
krypton, xenon, and methane are presented in Tab. 1. These values have been obtained from reference [11].

To set up the EoS parameters, the regression procedure takes also into account the isofugacity condition along the solid-liquid, solid-vapor, and liquid-vapor equilibrium branches of a pure compound. The procedure has been deeply presented in a previous article [8].

SLE, SVE, and VLE values for pure compounds have been generated from accurate auxiliary equations [11], considering these values as true equilibrium values. These auxiliary equations are precise correlations of the available experimental data, then in this work it has been considered that comparing the model with the values obtained from the auxiliary equations (referred to as auxiliary values) is equivalent to compare the model to experimental data.

For each substance, the P-T range used for the regression of the parameters extends from a minimum on the SVE branch to a maximum on the SLE branch. These values are presented in Tab. 2.

The EoS parameters for the six compounds, obtained applying the regression procedure [8] in the temperature-pressure ranges of Tab. 2, have been reported in Tab. 3 .

The comparison of the phase equilibrium values calculated with the SLV-EoS and the values obtained from the auxiliary equations is presented in Tab. 4. Tab. 4 represents the deviations obtained calculating the equilibrium temperature at fixed pressure; for each kind of equilibrium, $\mathrm{N}$ is the number of auxiliary values used for the comparison. In Tab. 4, the lines marked as overall represent the weighted average values of $\mathrm{AAD} \%$ and $\mathrm{Bias} \%$, and the maximum value of MAD\% considering all the pure substances.

For VLE the AAD averaged with respect to all the substances is about $0.1 \%$ with a Bias close to zero. The maximum value of MAD is $0.34 \%$. For SVE the AAD averaged with respect to all the compounds is $0.41 \%$. In this case the Bias is about $-0.1 \% .1 .52 \%$ is the maximum value of MAD, 
which is obtained for xenon. AAD for SLE is $0.49 \%$ with a Bias of about $-0.3 \%$. The maximum value of MAD is found for oxygen at very high pressures and it is about $2.3 \%$.

As an illustration, pressure-temperature equilibrium behaviors obtained with the SLV-EoS are represented in Figs. 2-3 for $\mathrm{N}_{2}$ and $\mathrm{Kr}$, respectively. Similar figures have been obtained for the other pure compounds. In Figs. 2-3, only a selected number of auxiliary values has been reported in order to make easier the visual comparison between auxiliary and calculated values.

\section{Extension of the equation of state to mixtures}

Extension of the SLV-EoS to mixtures has been considered using the mixing rules proposed by A. Yokozeki in reference [6], Eqs. (4)-(7). The thermodynamic consistency of the adopted mixing rules has been demonstrated in [8]. These mixing rules contain four binary interaction parameters, $k_{i j}, m_{i j}, n_{i j}$, and $l_{i j}$, where $k_{i i}=m_{i i}=n_{i i}=l_{i i}=0$.

$$
\begin{aligned}
& a=\sum_{i, j=1}^{N C} \sqrt{a_{i} a_{j}}\left(1-K_{i j}\right) x_{i} x_{j} \quad, \quad K_{i j}=\frac{k_{i j} k_{j i}\left(x_{i}+x_{j}\right)}{k_{i j} x_{j}+k_{j i} x_{i}} \\
& b=\frac{1}{2} \sum_{i, j=1}^{N C}\left(b_{i}+b_{j}\right)\left(1-m_{i j}\right) x_{i} x_{j} \\
& c=\frac{1}{2} \sum_{i, j=1}^{N C}\left(c_{i}+c_{j}\right)\left(1-n_{i j}\right) x_{i} x_{j} \\
& d=\frac{1}{2} \sum_{i, j=1}^{N C}\left(d_{i}+d_{j}\right)\left(1-l_{i j}\right) x_{i} x_{j}
\end{aligned}
$$

In Eqs. (4)-(7), $x$ is the mole fraction, subscripts $i$ and $j$ refer to pure compounds, and $N C$ is the number of components. 
The SLV-EoS, Eq. (1), with mixtures parameters from Eqs. (4)-(7) allows evaluating the partial molar fugacity coefficient of each component in a generic $\alpha$ phase, Eq. (8):

$$
\begin{aligned}
& \ln \varphi_{i}^{\alpha}(T, P, x)=\ln \left[\frac{v}{Z(v-b)(v-c)}\right]-\frac{2 \sqrt{a_{i}}}{R T v} \sum_{j=1}^{N C} \sqrt{a_{j}} x_{j}\left(1-k_{i j}\right)+ \\
& \frac{\left(-b+\sum_{j=1}^{N C}\left(b_{i}+b_{j}\right)\left(1-m_{i j}\right) x_{j}\right)}{c-b}\left[\frac{d-b}{v-b}+\frac{c-d}{c-b} \ln \left(\frac{v-b}{v-c}\right)\right]+ \\
& \frac{\left(-c+\sum_{j=1}^{N C}\left(c_{i}+c_{j}\right)\left(1-n_{i j}\right) x_{j}\right)}{c-b}\left[\frac{c-d}{v-c}+\frac{d-b}{c-b} \ln \left(\frac{v-b}{v-c}\right)\right]- \\
& \frac{\left(-d+\sum_{j=1}^{N C}\left(d_{i}+d_{j}\right)\left(1-l_{i j}\right) x_{j}\right)}{c-b} \ln \left(\frac{v-b}{v-c}\right)
\end{aligned}
$$

In Eq. (8), $Z$ is the compressibility factor, and the EoS parameters $a, b, c$, and $d$ are evaluated from Eqs. (4)-(7).

The necessary and sufficient condition to achieve equilibrium in a mixture is the global minimum of the Gibbs free energy of mixing, $g^{m}$, Eq. (9).

$$
g^{m}=\sum_{i=1}^{N C} x_{i} R T \ln \frac{x_{i} \varphi_{i}^{\alpha}(T, P, x)}{\varphi_{i}^{0}(T, P)}
$$

In Eq. (9), $\varphi_{\mathrm{i}}{ }^{\alpha}$ is the partial molar fugacity coefficient of component $i$ in the phase $\alpha$ at the temperature T and pressure $\mathrm{P}, \varphi_{\mathrm{i}}{ }^{0}$ is the fugacity of the pure component $i$ at the same $T$ and $P$ in its stable phase, $x_{i}$ is the molar fraction of component $i$ in the mixture. 
The binary interaction parameters of Eqs.(4)-(7) have been calculated starting from literature Lennard-Jones parameters of pure compounds, as explained below.

The Lennard-Jones model represents one of the most frequently used molecular interaction models for simple fluids of spherical and non polar molecules. It substantially gives the potential energy of a LJ fluid as a function of two parameters: $\sigma$, the collision diameter, and $\varepsilon$, the potential well depth. Modifications to the LJ model have been proposed for extending it to polar and nonspherical molecules.

In 1995, Cuadros et al. proposed a procedure to determine LJ parameters, based on molecular dynamics computer simulation results and the Soave-Redlich-Kwong Equation of State (SRKEoS), [12]. Same authors included a function of temperature and acentric factor in the SRK-EoS for extending the LJ model to non-spherical molecules thus obtaining the deviation of intermolecular potential from that of spherical molecules, [13]. As a result, in [13] LJ parameters are tabulated for spherical molecules (as $\mathrm{Ar}, \mathrm{Kr}$, and $\mathrm{Xe}$ ) as well as for diatomic (as $\mathrm{N}_{2}, \mathrm{O}_{2}, \mathrm{Cl}_{2}$ ) and multi-atomic molecules (as $\mathrm{C}_{10} \mathrm{H}_{22}, \mathrm{C}_{4} \mathrm{H}_{10} \mathrm{O}_{2}$ ).

Tab. 5 present the values of the parameters $\sigma$ and $\varepsilon / k_{B}$, where $k_{B}$ is the Boltzmann constant, for argon, oxygen, nitrogen, krypton, xenon, and methane as reported in [13].

For a generic binary mixture, $\sigma_{11}$ and $\varepsilon_{11}$ are referred to the component with the lower critical temperature. The critical temperatures of the fluids in Tab. 5 are indicated in Tab. 1.

The binary interaction parameters, $k_{i j}, m_{i j}, n_{i j}$, and $l_{i j}$, plotted as function of the ratio $\varepsilon_{11} / \varepsilon_{22}$ and $\sigma_{11} / \sigma_{22}$ have been presented in a previous article [9]. Starting from these diagrams, Eq. (10) can be obtained and used for expressing $k_{i j}, m_{i j}, n_{i j}$, and $l_{i j}$ as functions of $\sigma_{11} / \sigma_{22}$ and $\varepsilon_{11} / \varepsilon_{22}$. 


$$
\begin{aligned}
& z_{i j}=\sum_{t=1}^{3}\left(\frac{\varepsilon_{11}}{\varepsilon_{22}}\right)^{3-t}\left[A_{t 1}+A_{t 2}\left(\frac{\sigma_{11}}{\sigma_{22}}\right)^{2}\right]= \\
& =\left(\frac{\varepsilon_{11}}{\varepsilon_{22}}\right)^{2}\left[A_{11}+A_{12}\left(\frac{\sigma_{11}}{\sigma_{22}}\right)^{2}\right]+\left(\frac{\varepsilon_{11}}{\varepsilon_{22}}\right)\left[A_{21}+A_{22}\left(\frac{\sigma_{11}}{\sigma_{22}}\right)^{2}\right]+\left[A_{31}+A_{32}\left(\frac{\sigma_{11}}{\sigma_{22}}\right)^{2}\right]
\end{aligned}
$$

For a certain binary mixture, this equation allows evaluating a general binary interaction parameter, $\mathrm{z}_{\mathrm{ij}}\left(\mathrm{z}_{\mathrm{ij}}=k_{i j}, m_{i j}, n_{i j}, l_{i j}\right)$, knowing the two ratios $\sigma_{11} / \sigma_{22}$ and $\varepsilon_{11} / \varepsilon_{22}$ and the values of six coefficients $\left(A_{11}, A_{12}, A_{21}, A_{22}, A_{31}, A_{32}\right)$. The values of these coefficients for each binary interaction parameter are resumed in Tab. 6. It is worth noting that using a single functional form, Eq. (10), enables us to evaluate the four binary parameters just changing the values of the coefficients, reported in Tab. 6 .

The procedure presented above allows the evaluation of the binary interaction parameters directly from literature values of the pure compounds LJ parameters, [13], and from Eq. (10), thus any experimental value has been used for their regression.

In the next section, the SLV-EoS, Eq. (1), has been used with binary interaction parameters calculated from Eq. (10) for the prediction of solid-liquid equilibrium of a certain number of binary mixtures. Emphasis has been placed on the comparison between experimental and predicted values of solid-liquid equilibrium in temperature-composition diagrams, whereas the representation of other equilibrium properties is beyond the scope of this work. The calculation of the global minimum of the Gibbs free energy of mixing, Eq. (9), has been performed in order to find equilibrium compositions at imposed temperatures and pressures. 


\section{Solid-liquid equilibrium prediction for binary mixtures}

Figs. 4 to 10 represent the temperature-composition phase diagram of solid-liquid equilibrium for the following six binary mixtures: $\mathrm{Ar}-\mathrm{Kr}, \mathrm{Ar}-\mathrm{CH}_{4}, \mathrm{CH}_{4}-\mathrm{Kr}, \mathrm{N}_{2}-\mathrm{O}_{2}, \mathrm{~N}_{2}-\mathrm{Ar}$, and $\mathrm{Ar}-\mathrm{Xe}$. In Figs. 4 to 10, experimental values are indicated by empty symbols, while lines represent values calculated by the SLV-EoS, Eq. (1), using Eqs. (4) to (7) for evaluating the mixture parameters. The model with binary interaction parameters calculated from Eq. (10) is represented as continuous lines. The model with null binary interaction parameters has been represented for comparison (dashed lines). The values of the binary interaction parameters obtained from Eq. (10) and the corresponding ratios $\sigma_{11} / \sigma_{22}$ and $\varepsilon_{11} / \varepsilon_{22}$ are indicated in Tab. 7 for all the mixtures. Fig. 4 shows the isobaric equilibrium behavior for the mixture $\mathrm{Ar}-\mathrm{Kr}$. Experimental values are available for both the solid and the liquid equilibrium phases [14]. The solid phase for this system is a solid-solution with a quasi-azeotropic behavior where argon mole fraction approaches unity. The SLV-EoS, Eq. (1), with null binary interaction parameters (dashed lines in Fig. 4) predicts a solid-solution phase diagram, but it is not able to predict the quasi-azeotropic behavior close to pure argon.

The values of $\sigma_{11} / \sigma_{22}$ and $\varepsilon_{11} / \varepsilon_{22}$ obtained from the pure fluid literature values of $\sigma$ and $\varepsilon$ are 0.722 and 0.930 , respectively. The binary interaction parameters obtained using these values in Eq. (10) allow improving the qualitative representation of the solid-liquid equilibrium of $\mathrm{Ar}-\mathrm{Kr}$, predicting the quasi-azeotropic behavior close to pure argon (continuous lines in Fig. 4).

Fig. 5 shows the solid-liquid phase diagram for the mixture $\mathrm{Ar}-\mathrm{CH}_{4}$. Also in this case, experimental values are available for both the solid and the liquid equilibrium phases [15], [16]. The presence of experimental values of the liquid phase under the melting temperatures of pure $\mathrm{CH}_{4}$ and $\mathrm{Ar}$ indicates either an azeotrope or an eutectic with partial miscibility in the solid phase. 
At fixed mixture compositions, Fedorova realized heat capacity-temperature curves employing a calorimeter in order to observe the number of different crystals in a mixture [15]. In these measurements, each maximum in the curve corresponds to a crystal structure: two maxima mean two crystals with proper structure, while a single maximum means a single kind of crystal. Therefore, the first case involves an eutectic with partial miscibility between two solids, while the single maximum means a homogeneous crystal. In the case of the mixture $\mathrm{Ar}-\mathrm{CH}_{4}, \mathrm{Fedorova}$ found a single peak in the heat capacity-temperature curves for different concentrations of argon, always at temperatures lower than the melting temperature of pure argon. This fact suggested the author the presence of an azeotrope, which has been localized at about 0.6 in argon mole fraction, for which Fedorova obtained the highest maximum in his heat capacity-temperature curves. The presence of an azeotrope was previously suggested in 1937 by Veith and Schroeder, who did experimental work on the same system [17]. Their results have been omitted in Fig. 5 for sake of clarity.

Van't Zelde et al. [16] performed experimental works consisting in vapor-pressure measurements in an equilibrium cell concluding that the system presents an eutectic at $71.2 \mathrm{~K}$ and for 0.61 in argon mole fraction.

The SLV-EoS with null binary interaction parameters predicts a solid-solution behavior with a very thin solid-liquid equilibrium lens (see the dashed lines in Fig. 5). Thus, not only the quantitative prediction is erroneous, but also the qualitative representation is far from the real mixture behavior. In all the range of composition, Eq. (1) with binary interaction parameters equal to zero never gives a liquid phase stable at temperatures lower than the pure argon melting temperature.

The values of $\sigma_{11} / \sigma_{22}$ and $\varepsilon_{11} / \varepsilon_{22}$ obtained from the pure fluid literature values of $\sigma$ and $\varepsilon$ are 0.796 and 0.902 , respectively. The binary interaction parameters obtained using these values in Eq. (10) 
allow predicting a solid-liquid azeotrope at about $74.8 \mathrm{~K}$ and at 0.58 of argon mole fraction. Even if the liquid curves are qualitatively correct, the two solid-liquid lenses are thinner than the experimental lenses and the predicted azeotrope temperature is about $3 \mathrm{~K}$ higher than the experimental value.

Fig. 6 shows the solid-liquid equilibrium diagram for the mixture $\mathrm{CH}_{4}-\mathrm{Kr}$. Experimental values are available for both the solid and the liquid phase [17]. The solid phase is a solid-solution of methane and krypton.

For this system, both predictions obtained using the SLV-EoS (with binary interaction parameters equal to zero and calculated from Eq. (10)) are in a qualitative agreement with experimental values. In both cases the predicted solid-liquid equilibrium lens appears thinner than the experimental one.

The solid-liquid equilibrium for the system $\mathrm{N}_{2}-\mathrm{O}_{2}$ has been studied by Ruhemann et al. [18]. The experimental values concern only the composition of the liquid phase; it is then difficult to associate the real behavior to an azeotrope or an eutectic.

Fig. 7 shows the temperature-composition solid-liquid phase diagram predicted for the system $\mathrm{N}_{2}$ - $\mathrm{O}_{2}$; predicted values are not representative of the experimental behavior when null binary interaction parameters are used in Eq. (1). Furthermore, in this case a solid-solution is obtained. The mixture liquid phase is instead stable at temperatures lower than the pure melting temperature of oxygen (about $54 \mathrm{~K}$ ) when the ratios of $\sigma_{11} / \sigma_{22}$ and $\varepsilon_{11} / \varepsilon_{22}$ of Tab. 7 are used in Eq. (10) for predicting the binary interaction parameters. These values improve the qualitative prediction of the solid-liquid equilibrium behavior.

The experimental values for the mixture $\mathrm{N}_{2}-$ Ar concerning both the solid and the liquid phases are reported in Fig. 8. This system presents an azeotrope at about $62.7 \mathrm{~K}$ and at 0.8 of nitrogen mole fraction [19]. Long and Di Paolo [20] suggested the presence of partial miscibility in the 
solid phase in the range $0.55-0.60$ in nitrogen mole fraction (this area has been delimited by dotted lines in Fig. 8). These authors supposed two types of solids as a consequence of observed differences in the mode of freezing, which were encountered cooling alternatively nitrogen-rich and argon-rich mixtures.

The authors suggested that at about $63.5 \mathrm{~K}$ three phases coexist: two solids with different lattice structure and a liquid phase. In this case a peritectic behavior occurs seeing that the liquid phase is richer in nitrogen than both the solid phases.

Again, the prediction with null binary interaction parameters shows a solid-solution. Coupling the SLV-EoS and the binary interaction parameters obtained from the ratios $\sigma_{11} / \sigma_{22}$ and $\varepsilon_{11} / \varepsilon_{22}$ allows obtaining a prediction qualitatively representative of the experimental values. The azeotrope is calculated at $62.36 \mathrm{~K}$ and at about 0.81 in nitrogen mole fraction. The model does not predict the peritectic behavior and the partial immiscibility in the solid phase, but it is in agreement with the experimental values for both the liquid and the solid phase.

In 1960, Heastie and Lefebvre inferred the phase boundaries for the system $\mathrm{Ar}-\mathrm{Xe}$ from experimental measurements of the vapor pressure of the mixture, and the temperature of a calorimeter contained in an evacuated cryostat surrounded by liquid oxygen [21]. The authors suggested the presence of an eutectic, and the correspondent temperature-composition values are illustrated in Figs. 9-10. The eutectic point was determined at about $82.3 \mathrm{~K}$ and at 0.765 in argon mole fraction.

Fig. 9 shows the predicted phase diagrams for the mixture $\mathrm{Ar}-\mathrm{Xe}$, obtained using the SLV-EoS with binary interaction parameters equal to zero, graph (a), and calculated from Eq. (10), graph (b). The binary interaction parameters have been calculated using the ratios $\sigma_{11} / \sigma_{22}$ and $\varepsilon_{11} / \varepsilon_{22}$ reported in Tab. 7. In Figs. 9-10, horizontal lines represent temperatures where three phases coexist at equilibrium. 
Null binary interaction parameters do not make the SLV-EoS able to predict the partial miscibility in the solid phase. In this case, the mixture has only one homogeneous solid phase. Unlike this case, using the ratios $\sigma_{11} / \sigma_{22}$ and $\varepsilon_{11} / \varepsilon_{22}$ for calculating the binary interaction parameters allows obtaining the eutectic point, as shown in graph (b) of Fig. 9.

Zooms of the phase diagrams of Fig. 9 in the temperature range $74 \mathrm{~K}-94 \mathrm{~K}$ have been reported in graphs (a) and (b) of Fig. 10. Graphs 10 (a) and 10 (b) show the representations obtained with null and predicted binary interaction parameters, respectively. The vapor phase in equilibrium with the homogeneous solid phase, graph (a), and the solid phase rich in xenon $\left(\mathrm{S}_{2}\right)$, graph (b), is close to be pure argon. For this reason, the correspondent lines are not visible in Fig. 10.

With reference to graph (b) of Fig. 10, the model gives a solid-solid-liquid equilibrium at $80.2 \mathrm{~K}$. The two solid phases, one rich in argon $S_{1}$ and the other rich in xenon $S_{2}$, are partially immiscible. The mixture triple temperature is about $2 \mathrm{~K}$ lower than the eutectic temperature determined by Heastie and Lefebvre [21]. Furthermore, the SLV-EoS predicts a mole fraction of 0.84 in argon for the liquid phase, while in [21] the value is 0.765 . As a result, the slopes of the liquid branches of the $S_{1} L E$ and the $S_{2} L E$ do not correspond quantitatively with the trends of composition proposed in the literature. Nevertheless, the prediction obtained using binary interaction parameters from Eq. (10) respects the type of solid-liquid equilibrium behavior proposed in [21].

\section{Conclusions}

Literature models give good predictions of solid-liquid equilibrium for mixtures presenting eutectic behavior with total immiscibility in the solid phases, see for instance Prausnitz et al. [22]. For mixtures presenting miscibility in the solid phases, a variety of solid-liquid equilibrium behaviors can occur: solid solution, solid-liquid azeotrope, peritectic, and eutectic with partial 
miscibility. For these systems, the predictive models are less developed or not at all available. Moreover, few solid-liquid experimental data exist reporting also the composition of the solid phase. Knowing the solid-liquid behavior of mixtures is fundamental for designing new separation processes or for avoiding solid formation during certain processes. This paper tries to answer to the need of knowing, at list qualitatively, the solid-liquid behavior of mixtures for which solid miscibility (partial or total) occurs. The objective of this paper is setting up a method allowing predicting if a mixture forms solid solution, solid-liquid azeotrope, peritectic, or eutectic with partial miscibility.

This work is an application to real mixtures of the results obtained in reference [9] for mixtures of Lennard-Jones components for which the phase behavior was determined by molecular simulation. Analytical developments obtained from Ref. 9 allow predicting binary interaction parameters of the SLV-EoS, Eq. (1). Predicted binary interaction parameters allow obtaining qualitatively correct representations of the phase diagrams, involving solid phases, for real "simple" fluids. For real simple fluids are intended small molecules which behavior does not deviate considerably from the Lennard-Jones theory. The model has been applied to mixtures: Ar - $\mathrm{Kr}, \mathrm{Ar}-\mathrm{CH}_{4}, \mathrm{CH}_{4}-\mathrm{Kr}, \mathrm{N}_{2}-\mathrm{O}_{2}, \mathrm{~N}_{2}-\mathrm{Ar}$, and $\mathrm{Ar}-\mathrm{Xe}$. The proposed model is capable of predicting the qualitative solid-liquid behavior of the cited mixtures, distinguishing among the different types of phase diagrams. The developed model is useful for predicting the qualitative behavior of molecules involved in cryogenic processes like air distillation, natural gas treatment, or production of liquefied natural gas (LNG). Furthermore, solid-liquid-vapor equilibrium is produced with a single equation of state, allowing a consistent representation of the whole phase behavior and of the other thermodynamic properties. 


\section{Acknowledgements}

Authors are thankful to Air Liquide, Centre de Recherche Claude Delorme (France), for the financial support to the $\mathrm{PhD}$ thesis of $\mathrm{M}$. Campestrini.

\section{Nomenclature}

List of symbols

$a$

equation of state parameter

$a_{0}$

parameter in Eq. (2)

$a_{1}$

parameter in Eq. (2)

$a_{2}$

parameter in Eq. (2)

$A_{t 1}$

constant in Eq. (10)

$A_{t 2}$

constant in Eq. (10)

$b$

solid covolume $\left[\mathrm{m}^{3} / \mathrm{mol}\right]$

$b_{0}$

parameter in Eq. (3)

$b_{1}$

parameter in Eq. (3)

$b_{2}$

parameter in Eq. (3)

$c$

liquid covolume $\left[\mathrm{m}^{3} / \mathrm{mol}\right]$

$d$

equation of state parameter

g

molar Gibbs free energy

$k_{B}$

Boltzmann constant: $1.380648813 \times 10^{-23}[\mathrm{~J} / \mathrm{K}]$

$k$

binary interaction parameter

K

binary interaction parameter 
$l$

$m$

$n$

$N C$

$N_{A}$

$P$

$R$

$T$

$v$

$x$

$z$

Z

Greek letters

$\alpha$

$\varepsilon$

$\varphi$

$\sigma$

\section{Subscript}

$c$

$i$

$j$

$i j$

$j i$ binary interaction parameter

binary interaction parameter

binary interaction parameter

number of components in the mixture

Avogadro number: $6.022141793 \times 10^{23}[1 / \mathrm{mol}]$

pressure $[\mathrm{Pa}]$

gas constant: $R=N_{A} \cdot k_{B}[\mathrm{~J} /(\mathrm{mol} \cdot \mathrm{K})]$

temperature $[\mathrm{K}]$

molar volume $\left[\mathrm{m}^{3} / \mathrm{mol}\right]$

mole fraction

generic binary interaction parameter

compressibility factor

generic phase in a mixture

well depth in Lennard-Jones potential

fugacity coefficient

collision diameter in Lennard-Jones potential

related to the critical point

relative to the substance $i$

relative to the substance $j$

relative to the interaction between substance $i$ and the substance $j$

relative to the interaction between substance $j$ and the substance $i$ 
work)

$r \quad$ reduced property

$t \quad$ Related to the triple point

Superscript

$n$

parameter in Eq. (2)

$m$

parameter in Eq. (3)

Acronyms

AAD average absolute deviation

L liquid phase

MAD maximum absolute deviation

S solid phase

SLE Solid-liquid equilibrium

SVE solid-vapor equilibrium

V vapor phase

VLE vapor-liquid equilibrium

\section{References}

[1] A. Yokozeki, Int. J. Thermophys. 24 (2003) 589-620.

[2] A. Yokozeki, Applied Energy. 81 (2005) 334-349.

[3] A. Yokozeki, J. Thermophys. 26 (2005) 743-765.

[4] V. Vinš, A. Jäger, J. Hruby, R. Span, EPJ Web of Conferences 25, 01098 (2012).

[5] A. Yokozeki, Fluid Phase Equilib. 222-223 (2004) 55-56.

[6] A. Yokozeki, J. Thermophys. 25 (2004) 643-668. 
[7] A. Yokozeki, Applied Energy. 81 (2005) 322-333.

[8] P. Stringari, M. Campestrini, Coquelet C., Arpentinier P., Fluid Phase Equilib. 362 (2014) $258-267$.

[9] P. Stringari, M. Campestrini, Fluid Phase Equilib. 358 (2013) 68-77.

[10] P. Stringari, M. Campestrini, Coquelet C., Arpentinier P., Proceedings of the 12th IIR International Conference - Cryogenics 2012, Dresden, Germany, September, 2012.

[11] M.L. Huber, M.O. McLinden, E.W. Lemmon, NIST Standard Reference Database23, Reference Fluid Thermodynamic and Transport Properties-REFPROP, Version 8. 0, National Institute of Standards and Technology, Standard Reference Data Program, Gaithersburg, 2007.

[12] F. Cuadros, I. Cachadiña, W. Ahumada, Int. Rev. Phys. Chem. 14 (1995) 205-213.

[13] F. Cuadros, I. Cachadiña, W. Ahumada, Molecular Engineering 6 (1996) 319-325.

[14] R. Heastie, Nature, 176 (1955) 747-748.

[15] M.F. Fedorova, Zh. Eksp. Teor. Fiz. 8 (1938) 425-435.

[16] P. van't Zelfde, M.H. Omar, H.G.M. le Pair-Schroten, Z. Dokoupil, Physica 38 (1968) 241252.

[17] H. Veith, E. Schroeder, Z. Phys. Chem. Abt. A 179 (1937) 16-22.

[18] M. Ruhemann, A. Lichter, P. Komarov, Phys. Z. Sowjetunion 8 (1935) 326-336.

[19] F. Din, K. Goldmann, A.G. Monroe, Proc. 9 Int. Congr. Refr. (1955) 1003-1010.

[20] H.M. Long, F.S. Di Paolo, Bull. Int. Inst. Refr., Annexe 1 (1958) 253-265.

[21] R. Heastie, C. Lefebvre, Proc. Phys. Soc. 76 (1960) 180-184.

[22] J.M. Prausnitz, R.N. Lichtenthaler, E.G. de Azevedo, Molecular thermodynamics of fluidphase equilibria, 2nd edn., Chap. 9, Prentice-Hall, Englewood Cliffs, New Jersey, 1985. 
Table 1. Temperature and pressure at triple and critical points for $\mathrm{Ar}, \mathrm{O}_{2}, \mathrm{~N}_{2}, \mathrm{Kr}$, Xe, and $\mathrm{CH}_{4}$.

\begin{tabular}{lllll}
\hline Substance & $P_{t} / \mathrm{kPa}$ & $T_{t} / \mathrm{K}$ & $P_{c} / \mathrm{MPa}$ & $T_{d} / \mathrm{K}$ \\
\hline $\mathrm{Ar}$ & 68.891 & 83.8058 & 4.863 & 150.687 \\
$\mathrm{O}_{2}$ & 0.14628 & 54.361 & 5.043 & 154.581 \\
$\mathrm{~N}_{2}$ & 12.5198 & 63.151 & 3.3958 & 126.192 \\
$\mathrm{Kr}$ & 73.5 & 115.775 & 5.525 & 209.48 \\
$\mathrm{Xe}$ & 81.77 & 161.405 & 5.842 & 289.733 \\
$\mathrm{CH}_{4}$ & 11.697 & 90.694 & 4.5992 & 190.56 \\
\hline
\end{tabular}


Table 2. Temperature and pressure ranges for the regression of the parameters for Ar, $\mathrm{O}_{2}, \mathrm{~N}_{2}, \mathrm{Kr}, \mathrm{Xe}$, and $\mathrm{CH}_{4}$.

\begin{tabular}{|c|c|c|c|c|}
\hline \multirow{2}{*}{ Substance } & \multicolumn{2}{|l|}{ SVE } & \multicolumn{2}{|l|}{ SLE } \\
\hline & $P_{\min } / \mathrm{kPa}$ & $T_{\min } / \mathrm{K}$ & $P_{\max } / \mathrm{MPa}$ & $T_{\max } / \mathrm{K}$ \\
\hline $\mathrm{Ar}$ & 0.037 & 50 & 378 & 160 \\
\hline $\mathrm{O}_{2}$ & 0.013 & 48 & 1505 & 158 \\
\hline $\mathrm{N}_{2}$ & 0.042 & 44 & 399 & 127 \\
\hline $\mathrm{Kr}$ & 0.012 & 66 & 434 & 220 \\
\hline $\mathrm{Xe}$ & 0.017 & 90 & 438 & 300 \\
\hline $\mathrm{CH}_{4}$ & 0.016 & 60 & 594 & 200 \\
\hline
\end{tabular}


Table 3. Parameters of the SLV-EoS for $\mathrm{Ar}, \mathrm{O}_{2}, \mathrm{~N}_{2}, \mathrm{Kr}$, $\mathrm{Xe}$, and $\mathrm{CH}_{4}$.

\begin{tabular}{llllllllllllll}
\hline Substance & $\mathrm{Z}_{\mathrm{c}}$ & $\mathrm{b}_{\mathrm{c}}\left(10^{2}\right)$ & $\mathrm{b}_{0}$ & $\mathrm{~b}_{1}$ & $\mathrm{~b}_{2}$ & $\mathrm{~m}$ & $\mathrm{~d}\left(10^{2}\right)$ & $\mathrm{c}\left(10^{2}\right)$ & $\mathrm{a}_{\mathrm{c}}$ & $\mathrm{a}_{0}\left(10^{2}\right)$ & $\mathrm{a}_{1}$ & $\mathrm{a}_{2}$ & $\mathrm{n}$ \\
\hline $\mathrm{Ar}$ & 0.37507 & 3.121 & 0.331 & -0.148 & 2.870 & 1.046 & 3.202 & 3.299 & 0.1361 & 1.000 & 19.677 & 3.867 & 0.379 \\
$\mathrm{O}_{2}$ & 0.375006 & 3.157 & 0.333 & -0.161 & 4.207 & 0.677 & 3.180 & 3.209 & 0.1382 & 0.100 & 152.518 & 5.893 & 0.256 \\
$\mathrm{~N}_{2}$ & 0.37503 & 3.786 & 0.332 & -0.180 & 3.482 & 0.943 & 3.850 & 3.925 & 0.1367 & 1.000 & 27.663 & 4.207 & 0.364 \\
$\mathrm{Kr}$ & 0.37507 & 3.824 & 0.330 & -0.216 & 3.558 & 0.971 & 3.927 & 4.040 & 0.2315 & 1.130 & 17.227 & 3.737 & 0.395 \\
$\mathrm{Xe}$ & 3.7507 & 4.999 & 0.326 & -0.115 & 3.077 & 1.354 & 5.134 & 5.283 & 0.4189 & 0.971 & 16.382 & 3.710 & 0.399 \\
$\mathrm{CH}_{4}$ & 0.37504 & 4.258 & 0.335 & -0.334 & 4.201 & 0.682 & 4.422 & 4.468 & 0.2302 & 3.903 & 21.983 & 4.051 & 0.381 \\
\hline
\end{tabular}


Table 4. Summary of the statistical errors in calculating equilibrium temperatures at fixed pressures for $\mathrm{Ar}, \mathrm{O}_{2}, \mathrm{~N}_{2}, \mathrm{Kr}, \mathrm{Xe}$, and $\mathrm{CH}_{4}$. Deviations are evaluated with respect to the auxiliary equations.

\begin{tabular}{|c|c|c|c|c|c|c|c|c|c|c|c|c|}
\hline \multirow[t]{2}{*}{ Substance } & \multicolumn{4}{|l|}{ VLE } & \multicolumn{4}{|l|}{ SVE } & \multicolumn{4}{|l|}{ SLE } \\
\hline & $\mathrm{AAD} \%$ & Bias\% & MAD $\%$ & $\mathrm{~N}$ & $\mathrm{AAD} \%$ & Bias $\%$ & MAD $\%$ & $\mathrm{~N}$ & $\mathrm{AAD} \%$ & Bias\% & MAD $\%$ & $\mathrm{~N}$ \\
\hline$\overline{\mathrm{Ar}}$ & 0.08 & -0.02 & 0.20 & 107 & 0.35 & 0.34 & 0.55 & 35 & 0.26 & -0.06 & 1.04 & 116 \\
\hline $\mathrm{O}_{2}$ & 0.16 & -0.04 & 0.34 & 135 & 0.18 & 0.18 & 0.30 & 8 & 1.02 & -0.52 & 2.33 & 139 \\
\hline $\mathrm{N}_{2}$ & 0.10 & -0.03 & 0.24 & 102 & 0.25 & 0.25 & 0.34 & 21 & 0.45 & -0.19 & 1.19 & 104 \\
\hline $\mathrm{Kr}$ & 0.09 & -0.07 & 0.24 & 135 & 0.11 & 0.10 & 0.24 & 28 & 0.51 & -0.48 & 1.28 & 137 \\
\hline $\mathrm{Xe}$ & 0.09 & -0.05 & 0.22 & 167 & 0.78 & -0.64 & 1.52 & 73 & 0.42 & -0.28 & 1.47 & 174 \\
\hline $\mathrm{CH}_{4}$ & 0.11 & -0.07 & 0.26 & 130 & 0.03 & 0.01 & 0.06 & 32 & 0.26 & -0.01 & 0.51 & 141 \\
\hline Overall & 0.11 & -0.05 & 0.34 & & 0.41 & -0.13 & 1.52 & & 0.49 & -0.26 & 2.33 & \\
\hline
\end{tabular}


Table 5. Values of the LJ parameters $\sigma$ and $\varepsilon / k_{B}$ for $\mathrm{Ar}, \mathrm{O}_{2}, \mathrm{~N}_{2}, \mathrm{Kr}, \mathrm{Xe}$, and $\mathrm{CH}_{4}$ [13].

\begin{tabular}{llc}
\hline Substance & $\sigma / \AA ̊$ & $\varepsilon k_{B}^{-1} / \mathrm{K}$ \\
\hline $\mathrm{Ar}$ & 3.623 & 111.84 \\
$\mathrm{O}_{2}$ & 3.654 & 113.27 \\
$\mathrm{~N}_{2}$ & 3.919 & 91.85 \\
$\mathrm{Kr}$ & 3.895 & 154.87 \\
$\mathrm{Xe}$ & 4.26 & 213.89 \\
$\mathrm{CH}_{4}$ & 4.015 & 140.42 \\
\hline
\end{tabular}


Table 6. Coefficients of Eq. (10) for $\mathrm{z}_{\mathrm{ij}}=k_{i j}, m_{i j}, n_{i j}$, and $l_{i j}$.

\begin{tabular}{llllrrr}
\hline $\begin{array}{l}\text { Binary } \\
\text { interaction } \\
\text { parameter }\end{array}$ & $\mathrm{A}_{11}$ & $\mathrm{~A}_{12}$ & \multicolumn{1}{l}{$\mathrm{A}_{21}$} & \multicolumn{1}{c}{$\mathrm{A}_{22}$} & \multicolumn{1}{c}{$\mathrm{A}_{31}$} & \multicolumn{1}{c}{$\mathrm{A}_{32}$} \\
\hline $\mathrm{k}_{\mathrm{ij}}$ & -0.08547 & 8.35897 & 0.18555 & -18.6500 & -0.10008 & 9.141 \\
$\mathrm{~m}_{\mathrm{ij}}$ & 0.01675 & 4.58119 & -0.03522 & -8.2444 & 0.01847 & -0.537 \\
$\mathrm{n}_{\mathrm{ij}}$ & 0.05504 & 3.29914 & -0.13478 & -8.1611 & 0.07974 & 8.412 \\
$\mathrm{l}_{\mathrm{ij}}$ & 0.0253 & 4.49572 & -0.06244 & -11.4388 & 0.03714 & 8.093 \\
\hline
\end{tabular}


Table 7. Binary interaction parameters for the mixtures of interest in this work calculated from Eq.(8).

\begin{tabular}{|c|c|c|c|c|c|c|}
\hline \multirow{2}{*}{ Mixture } & \multicolumn{2}{|c|}{ Diameter and well-depth ratios } & \multicolumn{4}{|c|}{ Calculated Binary interaction parameter $\left(10^{2}\right)$} \\
\hline & $\sigma_{11} / \sigma_{22}$ & $\varepsilon_{11} / \varepsilon_{22}$ & $k_{i j}$ & $m_{i j}$ & $n_{i j}$ & $l_{i j}$ \\
\hline $\mathrm{Ar}-\mathrm{Kr}$ & 0.722 & 0.930 & -1.0501 & -1.8231 & 3.1784 & 1.5859 \\
\hline $\mathrm{Ar}-\mathrm{CH}_{4}$ & 0.796 & 0.902 & -1.0427 & -3.8966 & 4.5482 & 2.0943 \\
\hline $\mathrm{CH}_{4}-\mathrm{Kr}$ & 0.907 & 1.031 & -0.2959 & -0.3724 & 0.6319 & 0.2670 \\
\hline $\mathrm{N}_{2}-\mathrm{O}_{2}$ & 0.811 & 1.073 & -0.8374 & -2.1219 & 2.7486 & 1.2472 \\
\hline $\mathrm{N}_{2}-\mathrm{Ar}$ & 0.821 & 1.082 & -0.8931 & -2.7312 & 3.2438 & 1.4479 \\
\hline $\mathrm{Ar}-\mathrm{Xe}$ & 0.523 & 0.850 & 1.1016 & -7.5756 & 13.7155 & 8.6111 \\
\hline
\end{tabular}



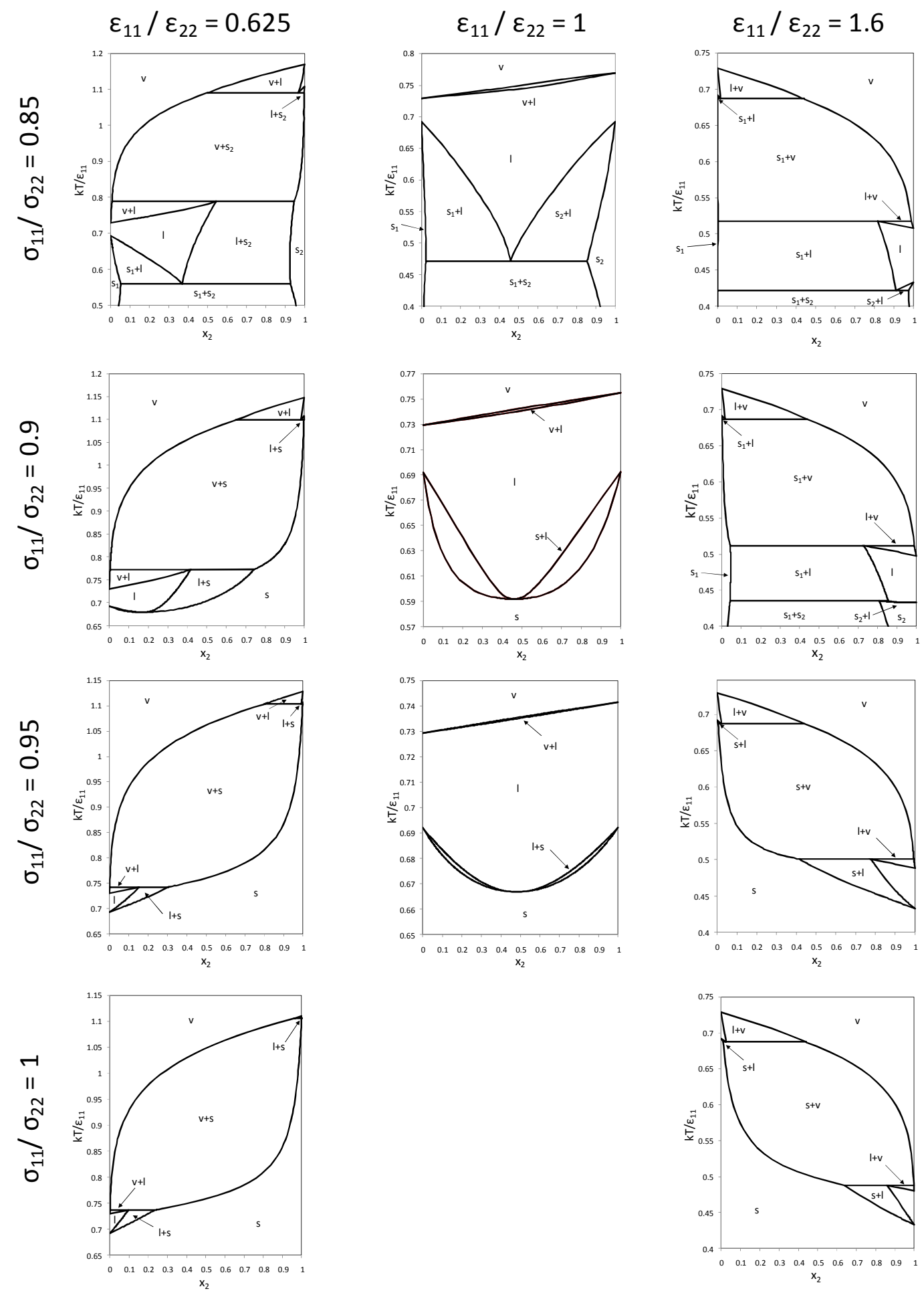

Figure 1. Reduced temperature vs. composition phase diagrams for Lennard-Jones binary mixtures with $\varepsilon_{11} / \varepsilon_{22}$ ranging from 0.625 and 1.6 and $\sigma_{11} / \sigma_{22}$ ranging from 0.85 to 1 at $P^{*}=$ 0.002. (-): LJ SLV-EoS model [9]. 


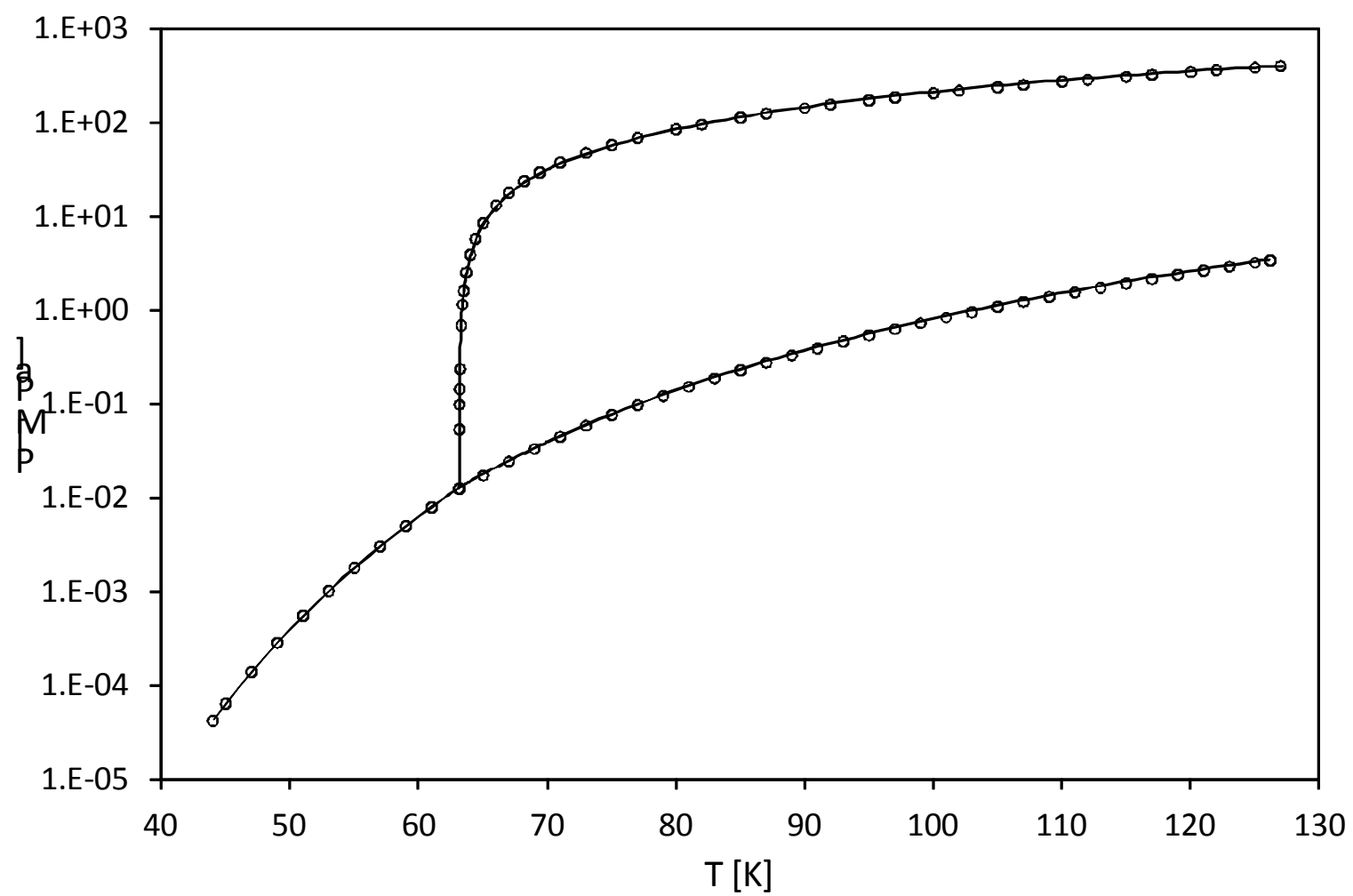

Figure 2. Pressure vs. temperature phase diagram for Nitrogen. (-): SLV-EoS; (O): auxiliary values [11]. 


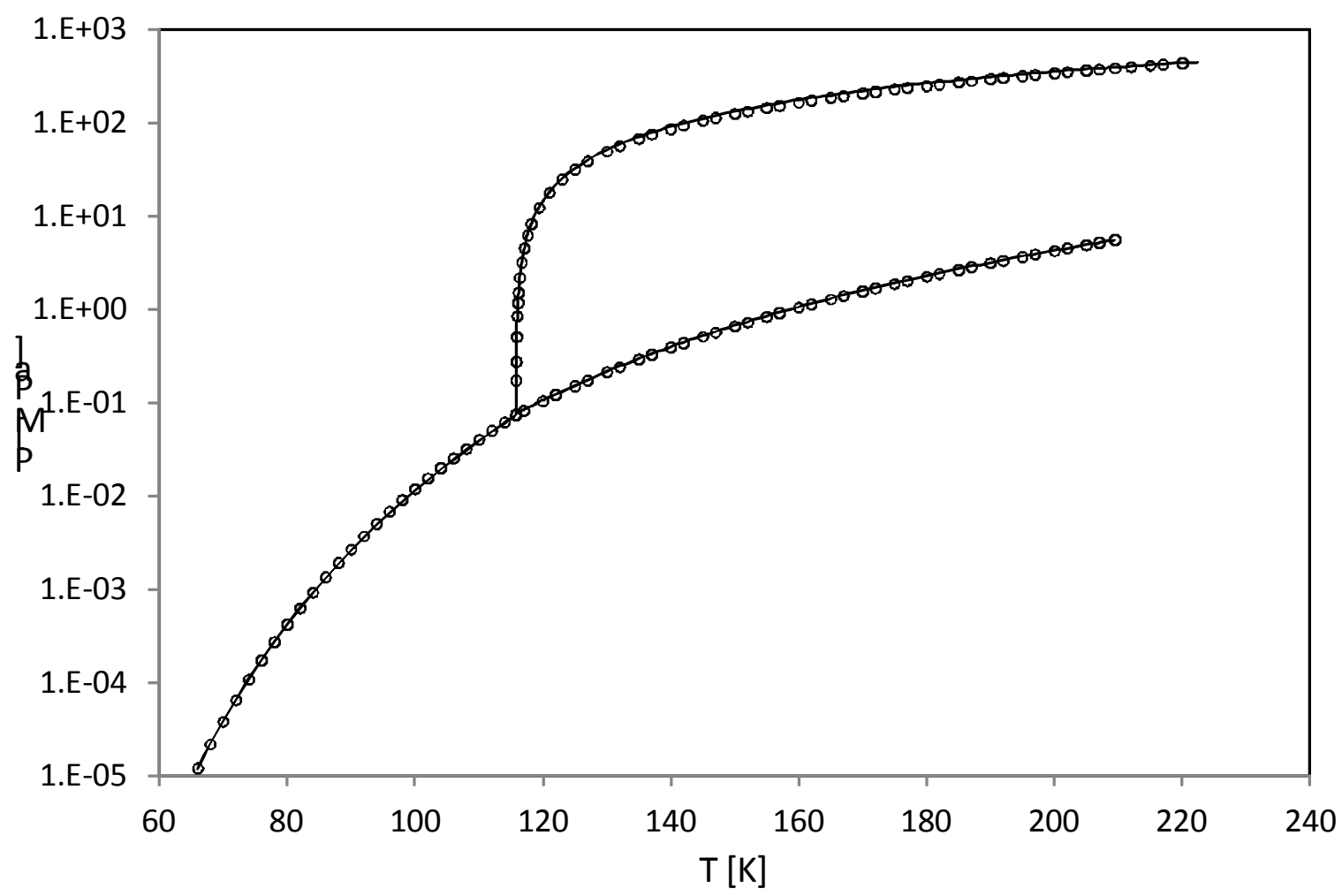

Figure 3. Pressure vs. temperature phase diagram for Krypton. (-): SLV-EoS; (०): auxiliary values [11]. 


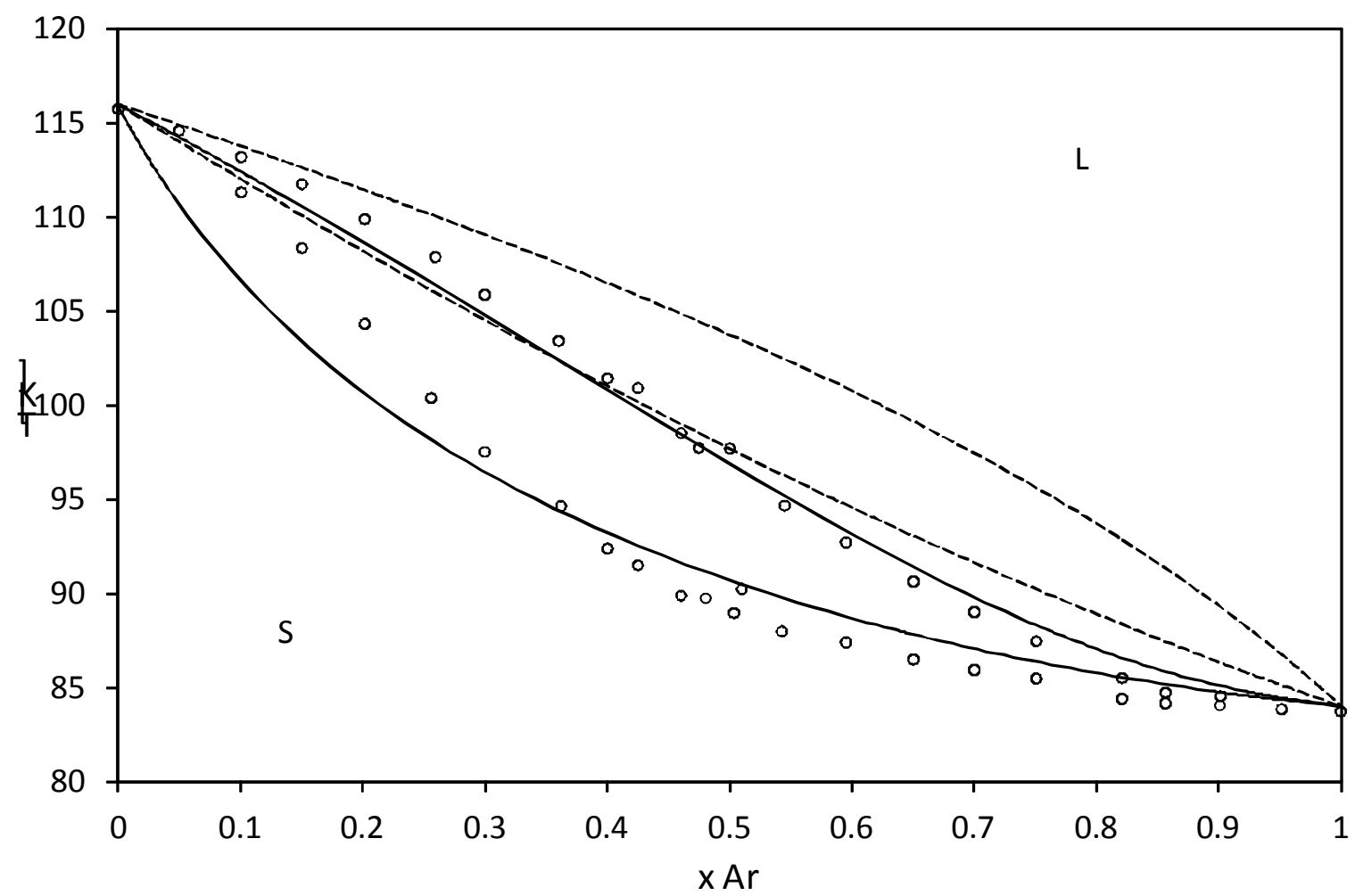

Figure 4. Solid-liquid equilibrium for the system $\mathrm{Ar}-\mathrm{Kr}$ in the temperature-composition diagram. SLV-EoS: (- -$)$ : null binary interaction parameters; (-): binary interaction parameters from Eq. (10). (०): experimental values from Heastie [14]. 


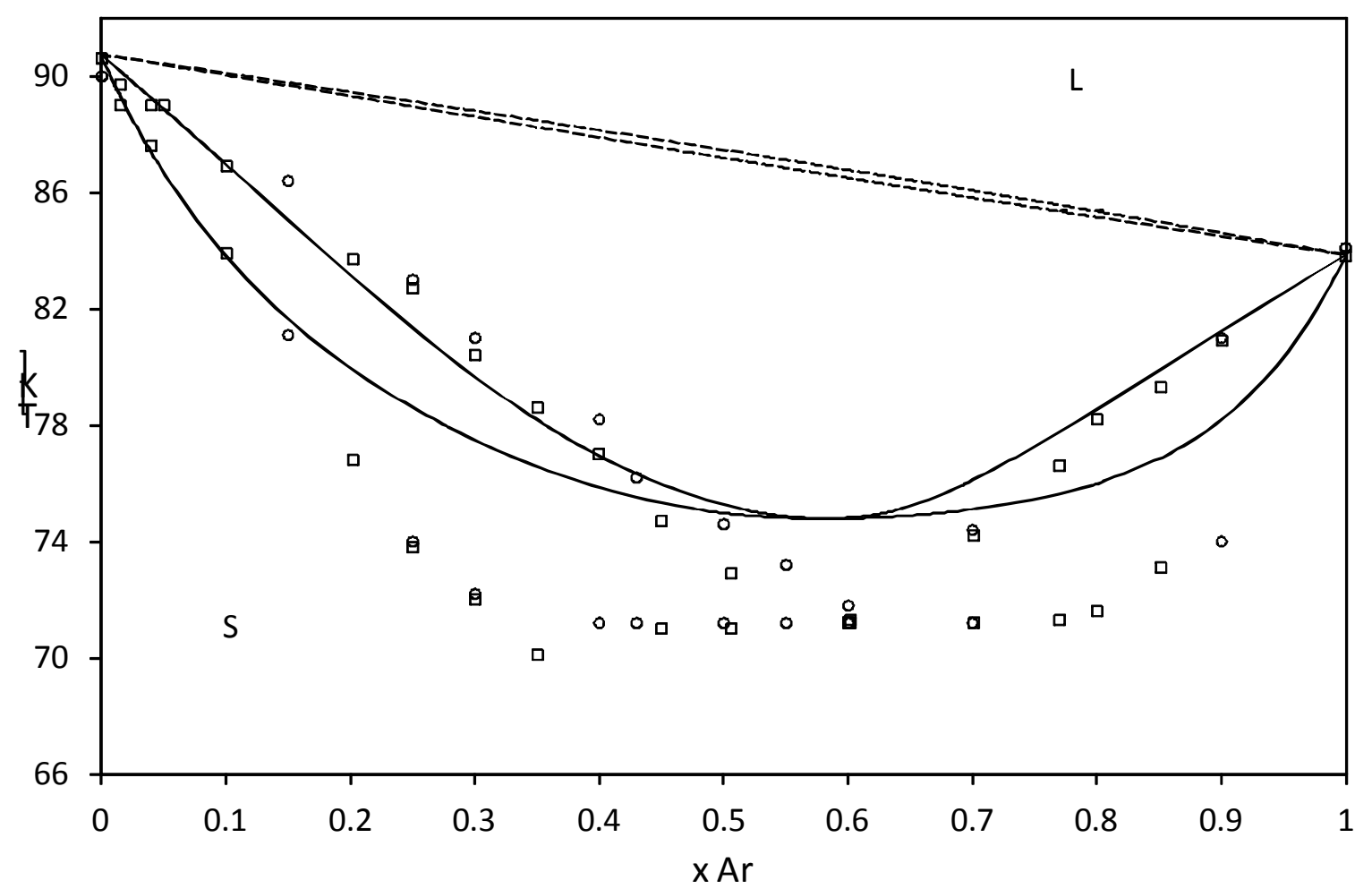

Figure 5. Solid-liquid equilibrium for the system $\mathrm{Ar}-\mathrm{CH}_{4}$ in the temperature-composition diagram. SLV-EoS: (- -): null binary interaction parameters; (-): binary interaction parameters from Eq. (10). Experimental values: (०): Fedorova [15]; (口): Zelde et al. [16]. 


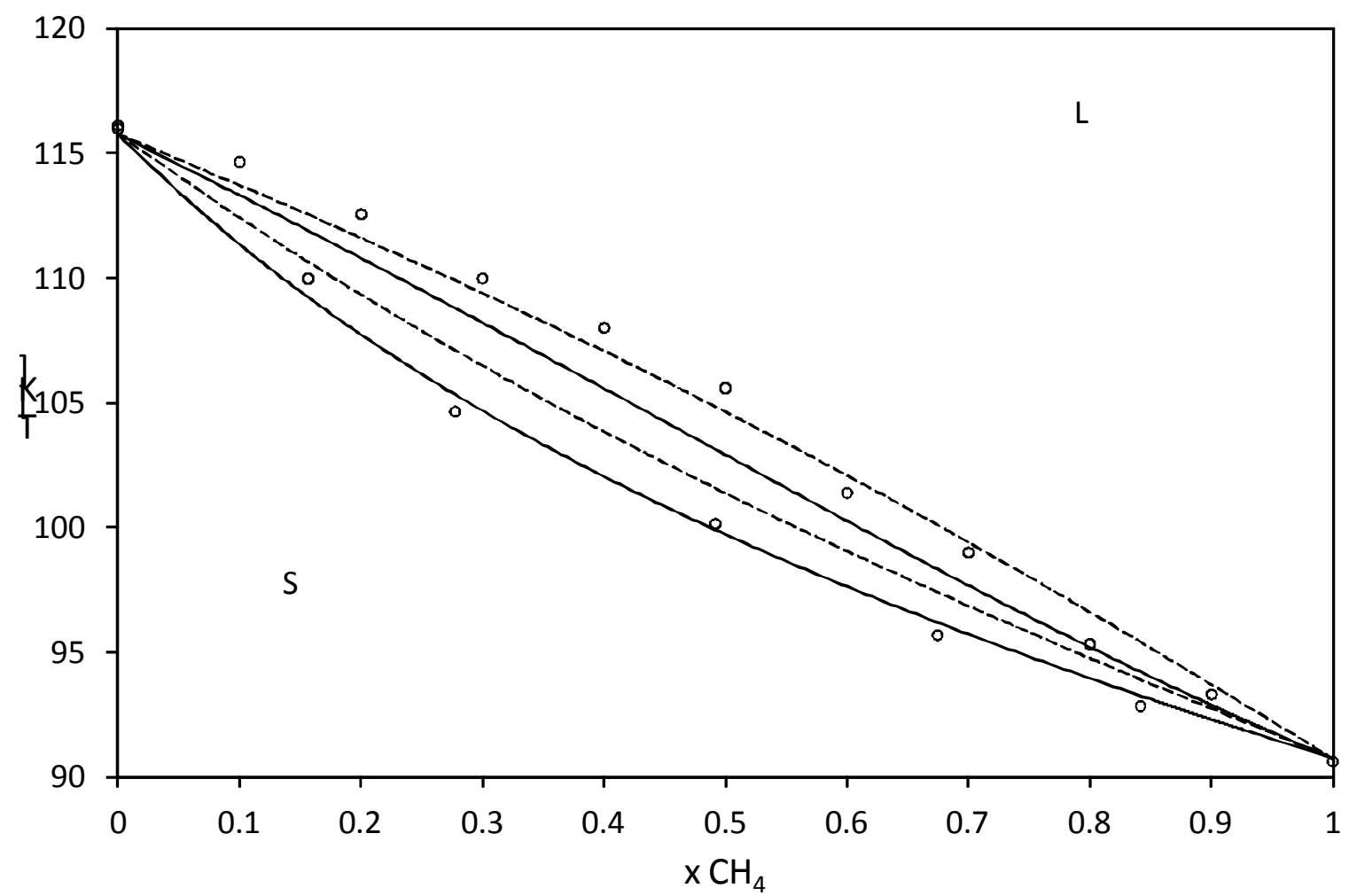

Figure 6. Solid-liquid equilibrium for the system $\mathrm{CH}_{4}-\mathrm{Kr}$ in the temperature-composition diagram. SLV-EoS: $(--)$ : null binary interaction parameters; (-): binary interaction parameters from Eq. (10). (०): experimental values from Veith and Schroeder [17]. 


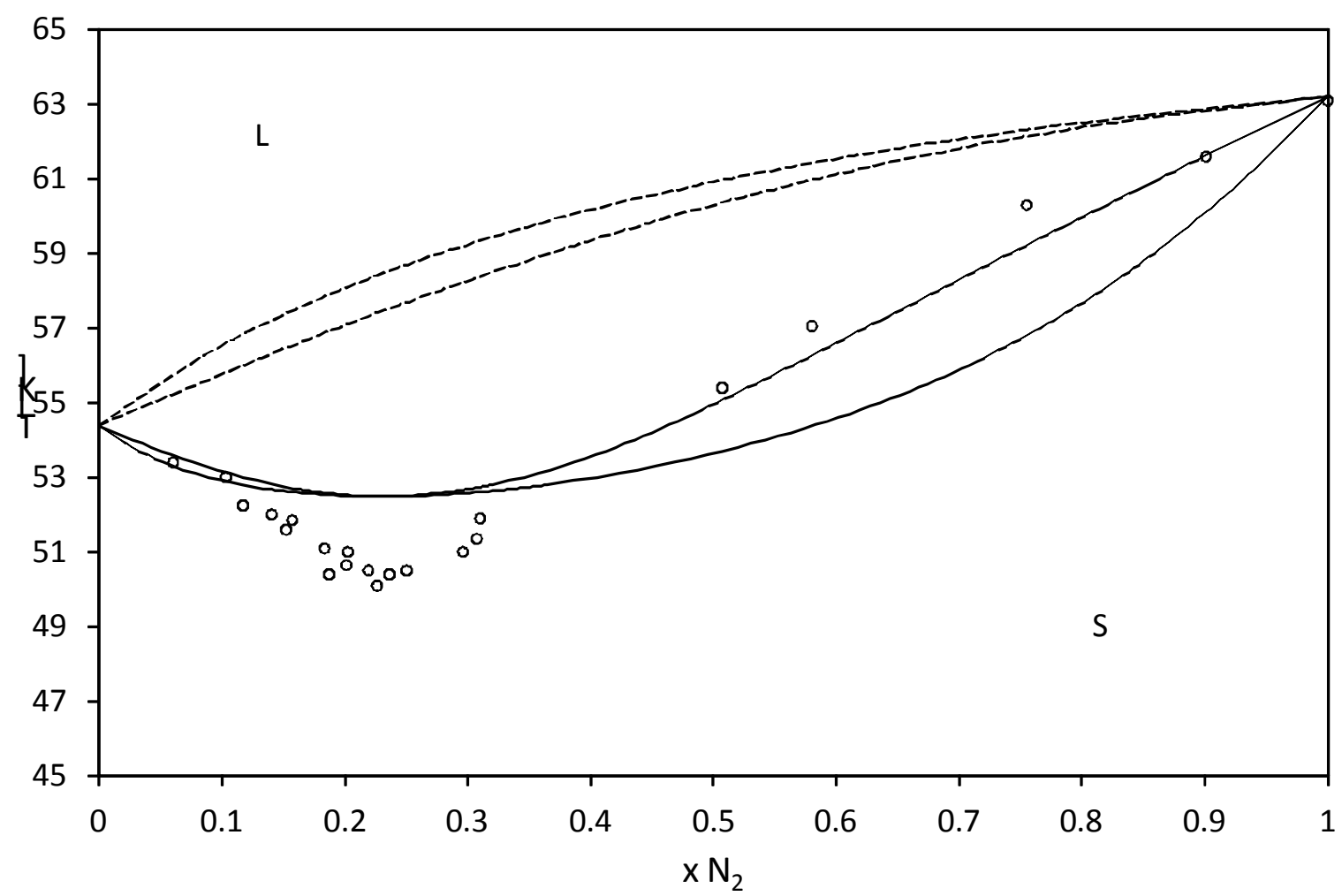

Figure 7. Solid-liquid equilibrium for the system $\mathrm{N}_{2}-\mathrm{O}_{2}$ in the temperature-composition diagram. SLV-EoS: $(--)$ : null binary interaction parameters; (-): binary interaction parameters from Eq. (10). (०): experimental values from Ruhemann et al. [18]. 


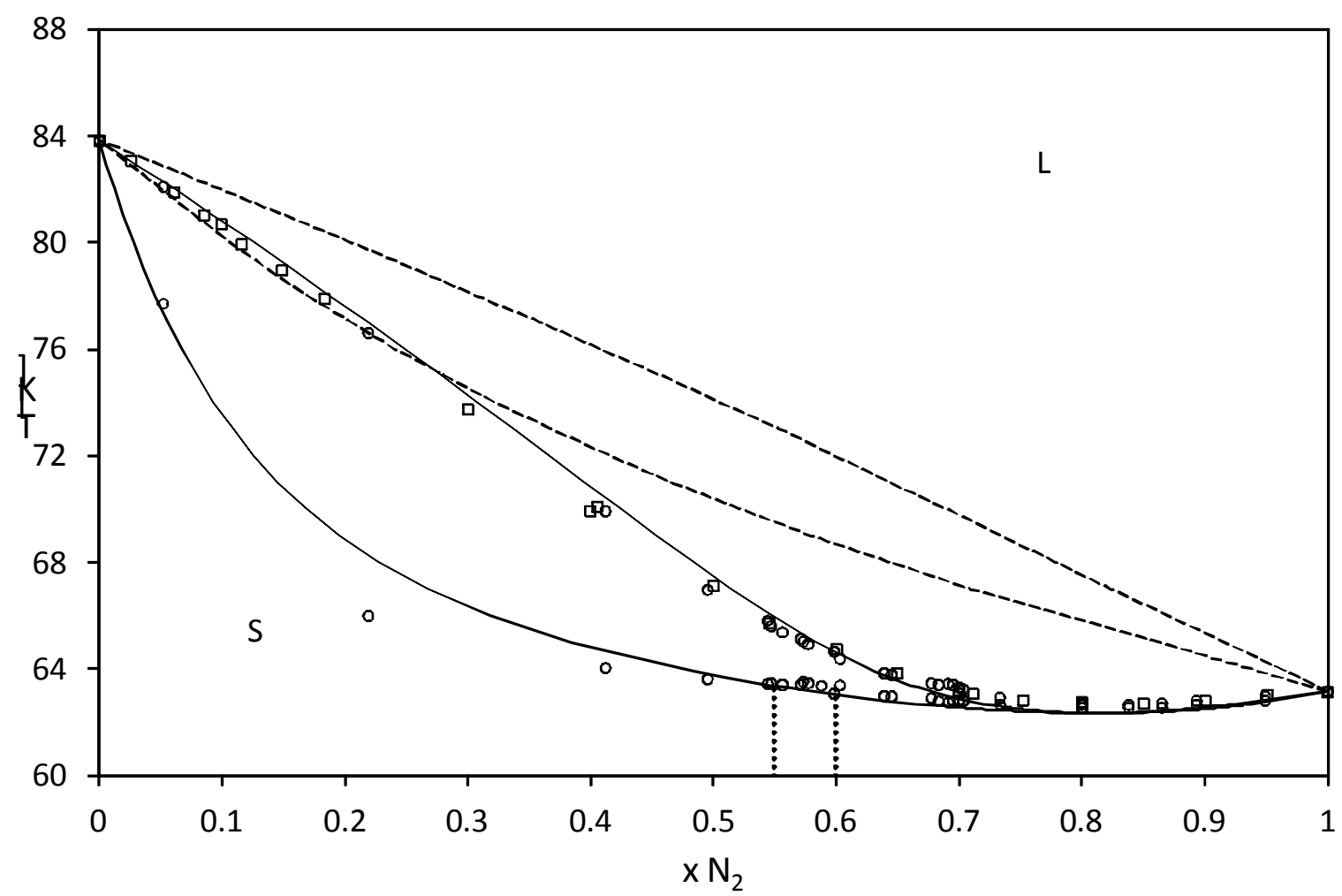

Figure 8. Solid-liquid equilibrium for the system $\mathrm{N}_{2}-\mathrm{Ar}$ in the temperature-composition diagram. SLV-EoS: (- -): null binary interaction parameters; (-): binary interaction parameters from Eq. (10). Experimental values: (口): Din et al. [19]; (०): Long and Di Paolo [20]; (-.): proposed solid-solid equilibrium by Long and Di Paolo [20]. 

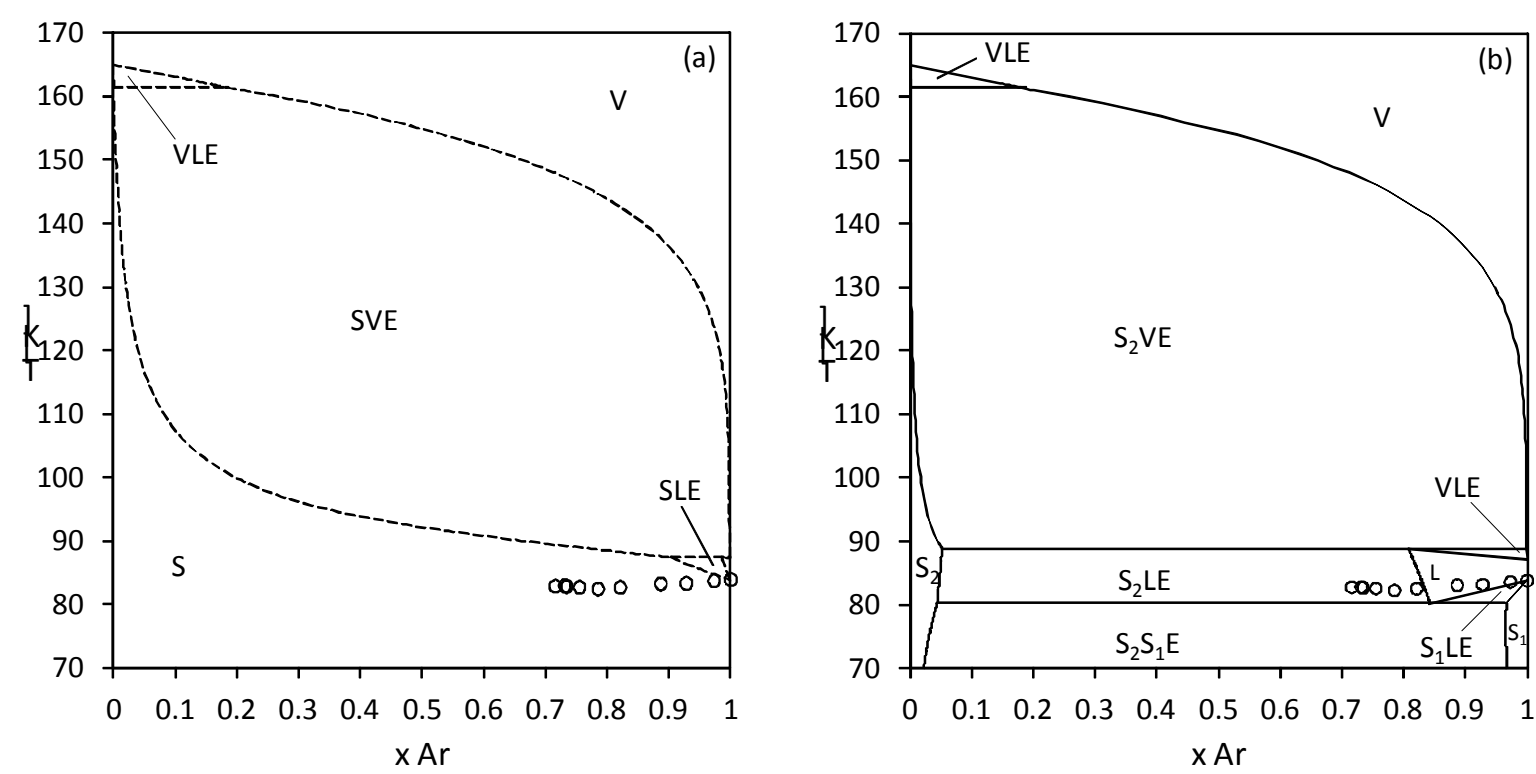

Figure 9. Temperature-composition equilibrium behavior for the system $\mathrm{Ar}-\mathrm{Xe}$. (a): SLV-EoS with null binary interaction parameters; (b): SLV-EoS with binary interaction parameters from Eq. (10). (०): experimental values from Heastie and Lefebvre [21]. 

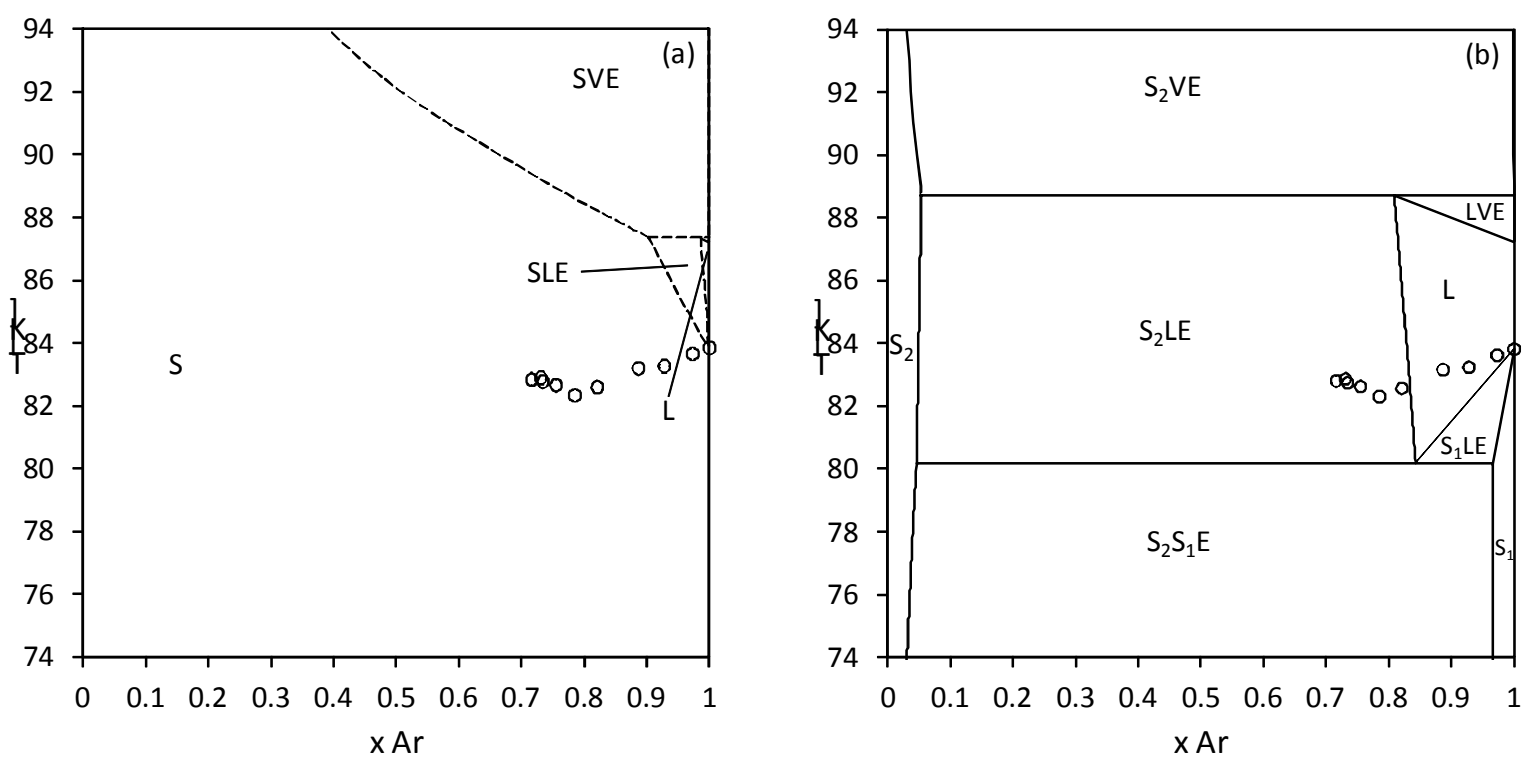

Figure 10. Temperature-composition equilibrium behavior for the system $\mathrm{Ar}-\mathrm{Xe}$ in the range 74 K - $94 \mathrm{~K}$. SLV-EoS with null binary interaction parameters; (b): SLV-EoS with binary interaction parameters from Eq. (10). (०): experimental values from Heastie and Lefebvre [21]. 